\title{
Electrophosphorescent homo- and heteroleptic copper(I) complexes prepared from various bis-phosphine ligands
}

\author{
Omar Moudam, ${ }^{a}$ Adrien Kaeser, ${ }^{a}$ Béatrice Delavaux-Nicot, ${ }^{a}$ Carine Duhayon, ${ }^{a}$ Michel Holler, ${ }^{b}$ Gianluca \\ Accorsi, ${ }^{c}$ Nicola Armaroli, ${ }^{* c}$ Isabelle Séguy, ${ }^{d}$ Jose Navarro, ${ }^{d}$ Pierre Destruel, ${ }^{* d}$ and Jean-François \\ ${ }_{5}$ Nierengarten $*^{a}$
}

\author{
Receipt/Acceptance Data [DO NOT ALTER/DELETE THIS TEXT] \\ Publication data [DO NOT ALTER/DELETE THIS TEXT] \\ DOI: 10.1039/b000000x [DO NOT ALTER/DELETE THIS TEXT]
}

Homo- and heteroleptic copper(I) complexes obtained from 10 various chelating bis-phosphine ligands and $\mathrm{Cu}\left(\mathrm{CH}_{3} \mathrm{CN}\right)_{4} \mathrm{BF}_{4}$. have been used for the preparation of light emitting devices.

The increasing market demand for low cost flat-panel displays and efficient lighting sources is a strong driving force for intensive research on organic light-emitting diodes (OLEDs). ${ }^{1}$ Fluorescent 15 semi-conducting polymers have been widely used for such applications. ${ }^{1}$ However, the internal quantum efficiency of the resulting devices is limited to $25 \%$ by the non-emissive triplet excitons produced in OLEDs based on singlet emitters. ${ }^{1}$ To overcome this problem, devices employing triplet emitters have 20 been developed in the past few years. ${ }^{2}$ Such OLEDs using phosphorescent heavy metal complexes can, in principle, reach a quantitative internal quantum efficiency as both singlet and triplet excitons participate to the emission owing to intersystem crossing of the singlet excited states to the triplet states. To date, the main 25 part of the electrophosphorescent materials used for OLED applications are complexes of noble metal ions such as $\mathrm{Ir}^{\mathrm{III}}, \mathrm{Pt}^{\mathrm{II}}$, $\mathrm{Ru}^{\text {II }}$ and $\mathrm{Os}^{\mathrm{II}}{ }^{2}$ Recent reports have however shown that inexpensive and non-toxic $\mathrm{Cu}^{\mathrm{I}}$ coordination compounds are also promising candidates for light emitting devices. ${ }^{3-6}$ As part of this 30 research, we became interested in electrophosphorescent heteroleptic $\mathrm{Cu}^{\mathrm{I}}$ complexes containing 1,10-phenanthroline (phen) and bis-phosphine (P-P) ligands. ${ }^{6,7}$ By changing systematically the nature of the chelating P-ligand, we found that some of them produce stable homoleptic $\mathrm{Cu}^{\mathrm{I}}$ complexes rather than the expected ${ }_{35} \mathrm{Cu}^{\mathrm{I}}(\mathrm{Phen})(\mathrm{P}-\mathrm{P})$ derivative. In this paper, we now report on a series of homo- and heteroleptic $\mathrm{Cu}(\mathrm{P}-\mathrm{P})_{2}$ compounds prepared on the basis of this initial finding. Whereas examples of homoleptic

\footnotetext{
${ }^{a}$ Laboratoire de Chimie de Coordination du CNRS (UPR 8241), 205 route de Narbonne, 31077 Toulouse Cedex 4, France. Fax: 33 (0) 56155 30 03; Tel: 33 (0) 56133 31 51; E-mail: jfnierengarten@lcc-toulouse.fr ${ }^{b}$ Laboratoire de Physico-Chimie Bioinorganique, ULP-CNRS (UMR 7177), Institut de Chimie, ECPM, 25 rue Becquerel, 67087 Strasbourg Cedex 2, France.

${ }^{c}$ Istituto per la Sintesi Organica e la Fotoreattività, Molecular Photoscience Group, Consiglio Nazionale delle Ricerche, Via Gobetti 101, 40129 Bologna, Italy; Fax: 3905163998 44; Tel: 3905163998 20;E-mail: armaroli@isof.cnr.it

${ }^{d}$ Laboratoire Plasma et Conversion d'Energie (LAPLACE), UPS-CNRS (UMR 5213), 118 route de Narbonne, 31062 Toulouse Cedex 9, France. Fax: 33 (0) 5615564 52; Tel: 33 (0) 5615562 61; E-mail:

Pierre.destruel@laplace.ups-tlse.fr

$\dagger$ Electronic Supplementary Information (ESI) available: Experimental details for the preparation of the compounds. See http://dx.doi.org/10.1039/b000000x/
}

$\mathrm{Cu}^{\mathrm{I}}(\mathrm{P}-\mathrm{P})_{2}$ derivatives have been already described, ${ }^{8}$ analogous heteroleptic $\mathrm{Cu}^{\mathrm{I}}$ complexes combining two different P-P ligands 40 have never been reported to the best of our knowledge. Finally, we also show that some of these compounds are promising materials for OLED applications.

$\mathrm{Cu}^{\mathrm{I}}(\mathrm{Phen})(\mathrm{P}-\mathrm{P})$ derivatives are usually prepared by reaction of 1,10-phenanthroline with a 1:1 mixture of the bis-phosphine ligand 45 and a $\mathrm{Cu}^{\mathrm{I}}$ salt such as $\mathrm{Cu}\left(\mathrm{CH}_{3} \mathrm{CN}\right)_{4} \mathrm{BF}_{4}$. When this standard procedure was applied to 1,2-bis(diphenylphosphino)benzene (dppb) and bis(diphenylphosphino)methane (dppm), the formation of the expected $\mathrm{Cu}^{\mathrm{I}}(\mathrm{Phen})(\mathrm{P}-\mathrm{P})$ derivatives was not observed. Actually, the homoleptic complexes $\mathrm{Cu}^{\mathrm{I}}(\mathrm{dppb})_{2}(\mathbf{1})$ and $\mathrm{Cu}^{\mathrm{I}}(\mathrm{dppm})_{2}$ 50 (2) were thus produced as their tetrafluoroborate salts. The structural assignement of $\mathbf{1}$ and $\mathbf{2}$ thus obtained was deduced from their ${ }^{31} \mathrm{P}\{\mathrm{H}\}$ NMR spectra displaying a sharp singlet at $\delta 8.1$ and $7.3 \mathrm{ppm}$, respectively. The structure of both $\mathbf{1}$ and $\mathbf{2}$ was further confirmed by mass spectrometry. The expected molecular ion 55 peaks were observed at $\mathrm{m} / \mathrm{z} 955.7$ for $\mathbf{1}\left(\left[M-\mathrm{BF}_{4}^{-}\right]^{+}\right.$, calcd for $\mathrm{C}_{60} \mathrm{H}_{48} \mathrm{P}_{4} \mathrm{Cu}:$ 955.20) and 831.2 for $2\left(\left[M-\mathrm{BF}_{4}^{-}\right]^{+}\right.$, calcd for $\mathrm{C}_{50} \mathrm{H}_{44} \mathrm{P}_{4} \mathrm{Cu}$ : 831.17). Finally, it can be added that compounds 1 and 2 were obtained in good yields by reaction of dppb and dppm (2 equiv.), respectively, with $\mathrm{Cu}\left(\mathrm{CH}_{3} \mathrm{CN}\right)_{4} \mathrm{BF}_{4}$ (1 equiv.) in ${ }_{60} \mathrm{CH}_{2} \mathrm{Cl}_{2}$. For complex 1, crystals suitable for X-ray crystal-structure analysis were obtained by slow diffusion of $\mathrm{Et}_{2} \mathrm{O}$ into a $\mathrm{CH}_{2} \mathrm{Cl}_{2}$ solution of $1 . \dagger$ As shown in Fig. 1, the $\mathrm{Cu}^{\mathrm{I}}$ center adopts a highly distorded tetrahedral geometry as a result of the small bite angle of the dppb ligand $\left(84.7^{\circ}\right)$. It can be noted that the $\mathrm{Cu}$ atom lies on a ${ }_{65}$ two fold axis. The $\mathrm{Cu}-\mathrm{P}$ distances are in the range expected from other known structures. ${ }^{8}$

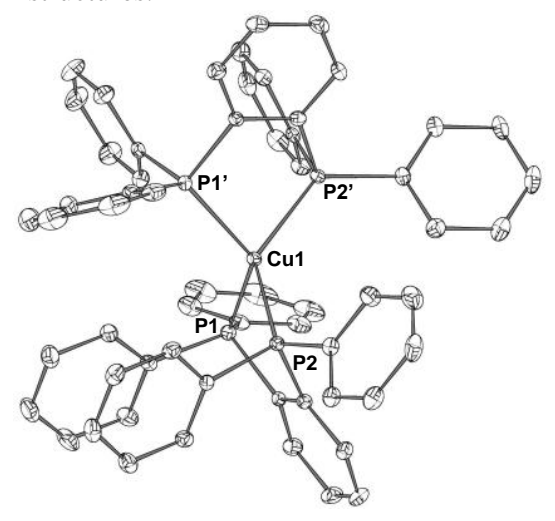

Fig. 1. ORTEP plot of the structure of the cation in 1. Thermal elipsoids are drawn at the $30 \%$ probability level. The prime (') characters in the 70 atom labels indicate that these atoms are at equivalent position (3/2$\mathrm{x}, \mathrm{y}, 3 / 2-\mathrm{z})$. Selected bond lengths and bond angles: $\mathrm{Cu}(1)-\mathrm{P}(1): 2.3092(8)$ 
$\AA$; $\mathrm{Cu}(1)-\mathrm{P}(2): \quad 2.2907(9) \AA ̊ \AA \mathrm{P}(1)-\mathrm{Cu}(1)-\mathrm{P}(2): 84.72(3)^{\circ} ; \mathrm{P}(1)-\mathrm{Cu}(1)-$ $\mathrm{P}\left(1^{\prime}\right): \quad 122.59(5)^{\circ} ; \quad \mathrm{P}(1)-\mathrm{Cu}(1)-\mathrm{P}\left(2^{\prime}\right): \quad 120.94(3)^{\circ} ; \quad \mathrm{P}(2)-\mathrm{Cu}(1)-\mathrm{P}\left(2^{\prime}\right)$ : $127.85(5)^{\circ}$.

75

The attempted preparation of the $\mathrm{Cu}^{\mathrm{I}}(\mathrm{Phen})(\mathrm{P}-\mathrm{P})$ derivatives from dppm and dppb revealed a peculiar behavior for these two ligands. Effectively, the reaction of 1,10-phenanthroline (1 equiv.) with a 1:1 mixture of other bis-phosphine ligands (bis[280 (diphenylphosphino) phenyl]ether: POP; 1,2bis(diphenylphosphino)ethane: dppe; 1,3-bis(diphenylphosphino) propane: dppp) and $\mathrm{Cu}\left(\mathrm{CH}_{3} \mathrm{CN}\right)_{4} \mathrm{BF}_{4}$ in $\mathrm{CH}_{2} \mathrm{Cl}_{2}$ gave the expected $\mathrm{Cu}^{\mathrm{I}}(\mathrm{Phen})(\mathrm{P}-\mathrm{P})$ complexes. This difference maybe be explained by the differences in bite angles for the different chelating P-ligands.

${ }_{85}$ When this angle is small enough (dppm and dppb), the metal center can easily accommodate two ligands. In contrast, steric factors resulting from the wider $\mathrm{P}-\mathrm{Cu}-\mathrm{P}$ angle for the other bis-phosphines substantially destabilize the $\mathrm{Cu}(\mathrm{P}-\mathrm{P})_{2}$ derivative, thus preventing its formation under our experimental conditions.

90 In principle, by replacing the phen ligand with dppm or dppb in the reaction sequence used to prepare the $\mathrm{Cu}^{\mathrm{I}}(\mathrm{Phen})(\mathrm{P}-\mathrm{P})$ derivatives, heteroleptic $\mathrm{Cu}^{\mathrm{I}}(\mathrm{P}-\mathrm{P})_{2}$ complexes should be obtained. This hypothesis was first tested by adding dppm (1 equiv.) to a 1:1 mixture of $\mathrm{POP}$ and $\mathrm{Cu}\left(\mathrm{CH}_{3} \mathrm{CN}\right)_{4} \mathrm{BF}_{4}$ in $\mathrm{CH}_{2} \mathrm{Cl}_{2}$. Complex ${ }_{95}\left[\mathrm{Cu}(\mathrm{POP})(\mathrm{dppm}) \mathrm{BF}_{4}(3)\right.$ was effectively thus obtained in a good yield $(80 \%)$. The ${ }^{31} \mathrm{P}\{\mathrm{H}\}$ NMR spectrum of $\mathbf{3}$ revealed two signals at $\delta-4.4$ and $-8.9 \mathrm{ppm}$ in good agreement with the proposed structure. It is worth noting that no detectable changes were observed in the ${ }^{31} \mathrm{P}\{\mathrm{H}\}$ NMR spectrum of a $\mathrm{CD}_{3} \mathrm{CN}$ solution of $\mathbf{3}$ 100 after one week, thus showing that there is no ligand exchange in solution. X-ray quality crystals of $\mathbf{3}$ were obtained by vapor diffusion of $\mathrm{Et}_{2} \mathrm{O}$ into a $\mathrm{CH}_{2} \mathrm{Cl}_{2}$ solution of the complex.t The asymmetric unit of the crystal structure contains two complexes of 3 in two different conformations along with one unit-occupancy 105 and one 0.5-occupancy $\mathrm{CH}_{2} \mathrm{Cl}_{2}$ molecules. As shown in Fig. 3, the structure of $\mathbf{3}$ reveals a highly distorted tetrahedral coordination environment about $\mathrm{Cu}^{\mathrm{I}}$ with $\mathrm{P}-\mathrm{Cu}-\mathrm{P}$ bond angles ranging from $73.28(12)$ to $125.43(13)^{\circ}$. It can be noted that the POP ligand is bound to the metal only through its pair of $\mathrm{P}$ donor atoms, the ether ${ }_{110} \mathrm{O}$ atom being at a nonbonding distance from the $\mathrm{Cu}(\mathrm{I})$ center $(>3.1$ A).

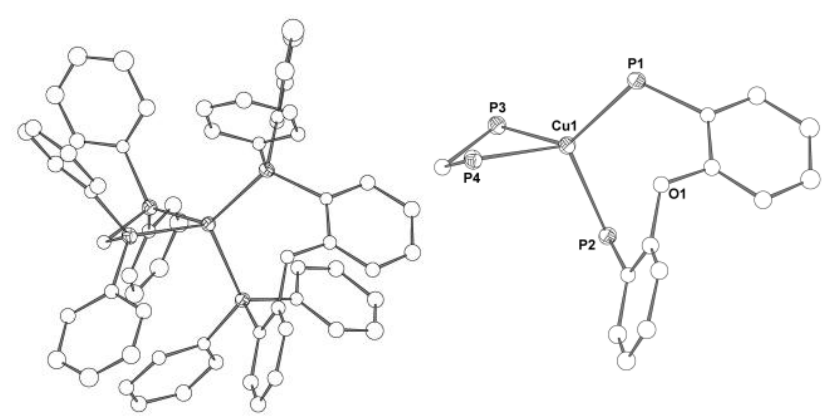

Fig. 2. Left: plot of the structure of the cation in $\mathbf{3}$ (only one conformer is 115 shown). Right: details of the coordination sphere around the $\mathrm{Cu}^{\mathrm{I}}$ cation. Thermal elipsoids are drawn at the $30 \%$ probability level, only the $\mathrm{Cu}$ and $\mathrm{P}$ atoms were refined anisotropically. Selected bond lengths and bond angles: $\mathrm{Cu}(1)-\mathrm{P}(1): 2.279(4)$; $\mathrm{Cu}(1)-\mathrm{P}(2): 2.304(3) ; \mathrm{Cu}(1)-\mathrm{P}(3): 2.333(3)$; $\mathrm{Cu}(1)-\mathrm{P}(4)$ : 2.425(4); $\mathrm{P}(1)-\mathrm{Cu}(1)-\mathrm{P}(2): 110.51(13)^{\circ} ; \quad \mathrm{P}(1)-\mathrm{Cu}(1)-\mathrm{P}(3)$ : 120 124.44(13) ${ }^{\circ} ; \mathrm{P}(1)-\mathrm{Cu}(1)-\mathrm{P}(4): 125.43(13)^{\circ} ; \mathrm{P}(2)-\mathrm{Cu}(1)-\mathrm{P}(3): 109.77(13)^{\circ}$; $\mathrm{P}(2)-\mathrm{Cu}(1)-\mathrm{P}(4): 108.26(13)^{\circ} ; \mathrm{P}(3)-\mathrm{Cu}(1)-\mathrm{P}(4): 73.28(12)^{\circ}$.
Similarly, addition of dppb (1 equiv.) to 1:1 mixtures of various 125 bis-phosphine ligands (POP, dppe, dppp) and $\mathrm{Cu}\left(\mathrm{CH}_{3} \mathrm{CN}\right)_{4} \mathrm{BF}_{4}$ in $\mathrm{CH}_{2} \mathrm{Cl}_{2}$ gave the heteroleptic complexes 4-6 in good yields (Fig. 3). Their structure was confirmed by ${ }^{1} \mathrm{H},{ }^{13} \mathrm{C}$, and ${ }^{31} \mathrm{P}$ NMR spectroscopy, mass spectrometry and elemental analysis.
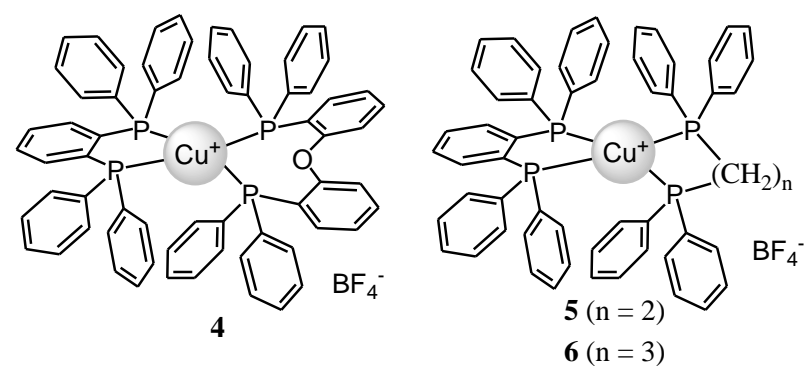

130 Fig. 3. Heteroleptic $\mathrm{Cu}^{\mathrm{I}}$ complexes 4-6.

The dppm containing derivatives $\mathbf{2}$ and $\mathbf{3}$ are oxygen sensitive. Indeed, when these compounds were stored without particular precaution, oxidation of the dppm ligand was observed. In contrast, 135 all the dppb-based complexes are stable under normal laboratory conditions. For this reason, only compounds 1 and 4-6 were further investigated. The electrochemical properties of these complexes were determined by cyclic voltammetry (CV) and Osteryoung Square Wave Voltammetry (OSWV). All the experiments were 140 performed at room temperature in $\mathrm{CH}_{2} \mathrm{Cl}_{2}$ solutions containing tetra- $n$-butylammonium tetrafluoroborate $(0.1 \mathrm{M})$ as supporting electrolyte, with a Pt wire as the working electrode and a saturated calomel electrode (SCE) as a reference. Potential data for all of the compounds are collected in Table 1 . In the cathodic region, a 145 ligand-centered reduction is observed at ca. $-2.2 \mathrm{~V} v$ s. SCE for all the compounds. In the anodic region, all the $\mathrm{Cu}^{\mathrm{I}}$ complexes show a first quasi-reversible one-electron process followed by an irreversible oxidation. The first wave is assigned to the oxidation of the $\mathrm{Cu}^{\mathrm{I}}$ cation while the second one corresponds to a ligand 150 centered process. The quite high potentials observed for the oxidation of the metal center indicate a good stabilization of these $\mathrm{Cu}^{\mathrm{I}}$ complexes. The positive shift seen for the first oxidation of 4 when compared to $\mathbf{1 , 5}$ and $\mathbf{6}$ is ascribed, at least in part, to the electron withdrawing effect of the diphenylether subunits of the ${ }_{155}$ POP ligand. However, it is also believed that complex $\mathbf{4}$ is less flexible owing to a more entangled structure resulting from the large bite angle of the rigid POP ligand. As a result, distortion towards a square planar coordination geometry upon oxidation of the $\mathrm{Cu}^{\mathrm{I}}$ center becomes more difficult in this particular case and the 160 corresponding $\mathrm{Cu}^{\mathrm{II}}$ complex is thus more destabilized .

Table 1. Electrochemical data of $\mathbf{1}, \mathbf{4 , 5}$, and $\mathbf{6}$ determined by OSWV on a Pt working electrode in $\mathrm{CH}_{2} \mathrm{Cl}_{2}+0.1 \mathrm{M}^{n} \mathrm{Bu}_{4} \mathrm{NBF}_{4}$ at room temperature. ${ }^{\mathrm{a}}$

\begin{tabular}{cccc}
\hline & $\mathrm{E}_{\text {ox1 }}$ & $\mathrm{E}_{\text {ox2 }}$ & $\mathrm{E}_{\text {Red1 } 1}$ \\
\hline $\mathbf{1}$ & +1.19 & +1.66 & -2.20 \\
$\mathbf{4}$ & +1.50 & +1.64 & -2.23 \\
$\mathbf{5}$ & +1.19 & +1.63 & -2.18 \\
$\mathbf{6}$ & +1.17 & +1.30 & -2.22 \\
\hline
\end{tabular}

${ }^{a}$ OSWVs were obtained using a sweep width of $20 \mathrm{mV}$, a frequency of 10 $165 \mathrm{~Hz}$, and a step potential of $5 \mathrm{mV}$.

The photoluminescence (PL) properties of $\mathrm{CH}_{2} \mathrm{Cl}_{2}$ solutions of $\mathbf{1 , 4} \mathbf{5}$ and $\mathbf{6}$ are summarized in Table 2 . The emission is tentatively 
assigned to metal-to-ligand charge transfer (MLCT) excited states ${ }^{5}$ 170 and appears to be substantially influenced by conformational changes from a pseudo-tetrahedral coordination geometry to a flattened structure in the excited state that may facilitate the formation of non-emissive penta-coordinated exciplexes as typically observed for $\mathrm{Cu}^{\mathrm{I}}$ complexes. ${ }^{9}$ Hence, the lifetime of 175 compound 4, for which this distortion is expected to be more difficult, is the longest and its emission quantum yield the highest. These observations are in agreement with the differences observed in the first oxidation potential of $\mathbf{4}$ when compared to $\mathbf{1 , 5}$ and $\mathbf{6}$ (vide supra). Whereas the emission quantum yields in solutions are 180 quite low, compounds $\mathbf{1}$ and $\mathbf{4}$ exhibit a bright luminescence in the solid state at room temperature as well as in rigid frozen $\mathrm{CH}_{2} \mathrm{Cl}_{2}$ solutions at $77 \mathrm{~K}$. Indeed, under these conditions, geometric distorsions prompting non-radiative deactivation of the MLCT excited states ${ }^{10}$ are prevented. This is further confirmed by the 50 $185 \mathrm{~nm}$ blue shift of the emission maxima when going from room temperature to $77 \mathrm{~K}$ for both $\mathbf{1}$ and $\mathbf{4}$. A similar trend is observed for $\mathbf{5}$ and $\mathbf{6}$, however the effect is less dramatic. Indeed, the less rigid dppe and dppp ligands may facilitate some excited-state distortion.

190

Table 2. Luminescence data in $\mathrm{CH}_{2} \mathrm{Cl}_{2}$ (air free solutions) at $298 \mathrm{~K}$

\begin{tabular}{cccc}
\hline & $\lambda_{\max }(\mathrm{nm})^{\mathrm{a}}$ & $\Phi_{\mathrm{em}}(\%)^{\mathrm{b}}$ & $\tau(\mathrm{ns})^{\mathrm{c}}$ \\
\hline $\mathbf{1}$ & 556 & $1.10^{-2}$ & 244 \\
$\mathbf{4}$ & 494 & 2 & 2440 \\
$\mathbf{5}$ & 546 & $2.10^{-2}$ & 231 \\
$\mathbf{6}$ & 544 & $8.10^{-2}$ & $2.5-5.8$ \\
\hline
\end{tabular}

${ }^{a}$ Emission maxima from uncorrected spectra, $\lambda_{\text {exc }}=330 \mathrm{~nm}$; ${ }^{\mathrm{b}}$ Emission quantum yields in air free solutions; ${ }^{\mathrm{c}}$ Excited state lifetimes.

195 Based on the PL data, complexes $\mathbf{1}$ and $\mathbf{4}$ were selected for light emitting device fabrication. Poly(vinyl carbazole) (PVK) was chosen as the host material because of its good hole-transport ability, broad band-gap and overlap of the emission spectra with the absorption spectra of $\mathbf{1}$ and 4 . The light emitting devices were 200 fabricated by spin coating a thin film of a $1: P V K$ or a $4: P V K$ blend (ca. $120 \mathrm{~nm}$ ) on an ITO substrate. The concentration of $\mathbf{1}$ and $\mathbf{4}$ in the PVK matrix was $12.5 \%$ in weight. After the film had been dried under vacuum at room temperature for $2 \mathrm{~h}$, the cathode was fabricated by thermal evaporation of an Al layer $(100 \mathrm{~nm})$. The 205 electroluminescence (EL) spectra of $\mathbf{1}$ and $\mathbf{4}$ in PVK films are displayed in Fig. 4.

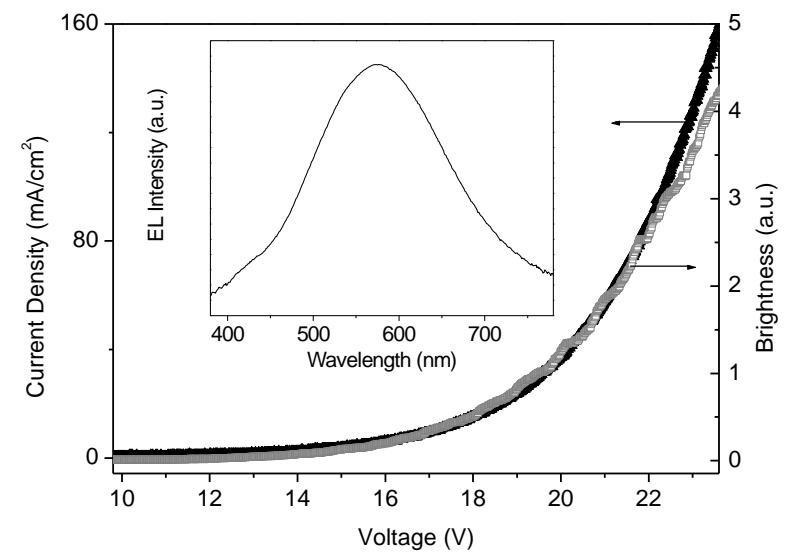

Fig. 4. I-V-B characteristics of the device obtained from 1. Inset: EL spectra of 1 at a concentration of 12.5 wt.-\% in a PVK matrix. 210

In both cases, the EL spectra are red shifted and significantly broader when compared to the PL spectra recorded in $\mathrm{CH}_{2} \mathrm{Cl}_{2}$ solutions (see ESI). As a result, almost white light is produced by both devices. The current-voltage-brightness (I-V-B) characteristics 215 (Fig. 4) of the devices prepared from $\mathbf{1}$ and $\mathbf{4}$ indicate both turn-on voltages of $15 \mathrm{~V}$ and maximum brightnesses of 490 (at $20 \mathrm{~V}$ for $\mathbf{1}$ ) and $330 \mathrm{~cd} \cdot \mathrm{m}^{-2}$ (at $20 \mathrm{~V}$ for 4). The device efficiencies have not been yet optimized, but they should be improved by using appropriate hole blocking and electron transfer layers in the device 220 configuration. Work in this direction is currently underway in our laboratories.

This work was supported by the CNR (commessa PM.P04.010, MACOL), the CNRS and the EU (contract n. IST-2002-004607, ${ }_{225}$ OLLA). We further thank A. Saquet for the CV and OSWV measurements.

\section{Notes and references}

$\dagger \mathrm{C}_{60} \mathrm{H}_{48} \mathrm{P}_{4} \mathrm{CuBF}_{4}\left(M_{\mathrm{r}}=1043.29\right)$, monoclinic space group $P 2 / \mathrm{n}, \mathrm{Z}=2, a$ $=13.5721(9), b=12.5841(8), c=14.9692(12) \AA, \alpha=90, \beta=100.516(6)$, $230 \gamma=90^{\circ}, V=2513.7(3) \AA^{3}, 308$ parameters, 11658 reflections measured, 5719 unique (Rint $=0.04), 3534$ reflections used in the calculations $[\mathrm{I}>2.5 \sigma], \mathrm{R}=0.0509, \mathrm{wR}=0.0579$. Full data collection parameters, and structural data are available as CIF file (Cambridge Crystallographic Data Centre deposition number CCDC 645319).

$235 \ddagger \mathrm{C}_{61.75} \mathrm{H}_{51.50} \mathrm{~B}_{1} \mathrm{Cl}_{1.50} \mathrm{Cu}_{1} \mathrm{~F}_{4} \mathrm{O}_{1} \mathrm{P}_{4}\left(M_{\mathrm{r}}=1137.01\right)$, triclinic space group $P$ - 1 , $\mathrm{Z}=4, a=14.6080(14), b=19.213(2), c=21.0316(17) \AA, \alpha=$ 80.126(11), $\beta=80.686(11), \gamma=89.676(12)^{\circ}, V=5737.2(10) \AA^{3}, 651$ parameters, 57446 reflections measured, 20986 unique $($ Rint $=0.09)$, 6820 reflections used in the calculations $[\mathrm{I}>2 \sigma], \mathrm{R}=0.0714$, $w \mathrm{R}=$ 240 0.0789. Full data collection parameters, and structural data are available as CIF file (Cambridge Crystallographic Data Centre deposition number CCDC 645318).

1 M. G. Harrison and R. H. Friend, in Electronic Materials: the Oligomer Approach (K. Müllen and G. Wegner, Eds.), Wiley-VCH, 245 1998, p. 515-558; K. Müllen and U. Scherf (Eds.), Organic Light Emitting Devices, Wiley-VCH, 2005.

2 For recent reviews, see: E. Holder, B. M. W. Langeveld and U. S. Schubert, Adv. Mater. 2005, 17, 1109; P.-T. Chou and Y. Chi, Chem. Eur. J. 2007, 13, 380.

2503 Y.-G. Ma, W.-H. Chan, X.-M. Zhou and C.-M. Che, New J. Chem. 1999, 23, 263; Y.Ma, C.-M. Che, H.-K. Chao, X. Zhou, W. H. Chan and J. Shen, Adv. Mater. 1999, 11, 852.

4 Q. Zhang, Q. Zhou, Y. Cheng, L. Wang, D. Ma, X. Jing and F. Wang, Adv. Mater. 2004, 16, 432; Q. Zhang, Q. Zhou, Y. Cheng, L.

255 Wang, D. Ma, X. Jing and F. Wang, Adv. Funct. Mater. 2006, 16, 1203.

5 A. Tsuboyama, K. Kuge, M. Furugori, S. Okada, M. Hoshino and K. Ueno, Inorg. Chem. 2007, 46, 1992.

6 N. Armaroli, G. Accorsi, M. Holler, O. Moudam, J.-F. Nierengarten, 260 Z. Zhou, R. T. Wegh and R. Welter, Adv. Mater. 2006, 18, 1313.

7 D. G. Cuttell, S. M. Kuang, P. E. Fanwick, D. R. McMillin and R. A. Walton, J. Am. Chem. Soc. 2002, 124, 6.

8 J. R. Black, W. Levason, M. D. Spicer and M. Webster, J. Chem. Soc., Dalton Trans. 1993, 3129; S. Kitagawa, M. Kondo, S. Kawata,

265 S. Wada, M. Maekawa and M. Munakata, Inorg. Chem. 1995, 34, 1455; P. Comba, C. Katsichtis, B. Nuber and H. Pritzkow, Eur. J. Inorg. Chem. 1999, 777; E. Szlyk, R. Kucharek, I. Szymanska and L. Pazderski, Polyhedron 2003, 22, 3389.

9 N. Armaroli, Chem. Soc. Rev. 2001, 30, 113 and references therein.

27010 D. Felder, J. F. Nierengarten, F. Barigelletti, B. Ventura, and N. Armaroli, J. Am. Chem. Soc., 2001, 123, 6291. 


\section{Graphical Abstract}

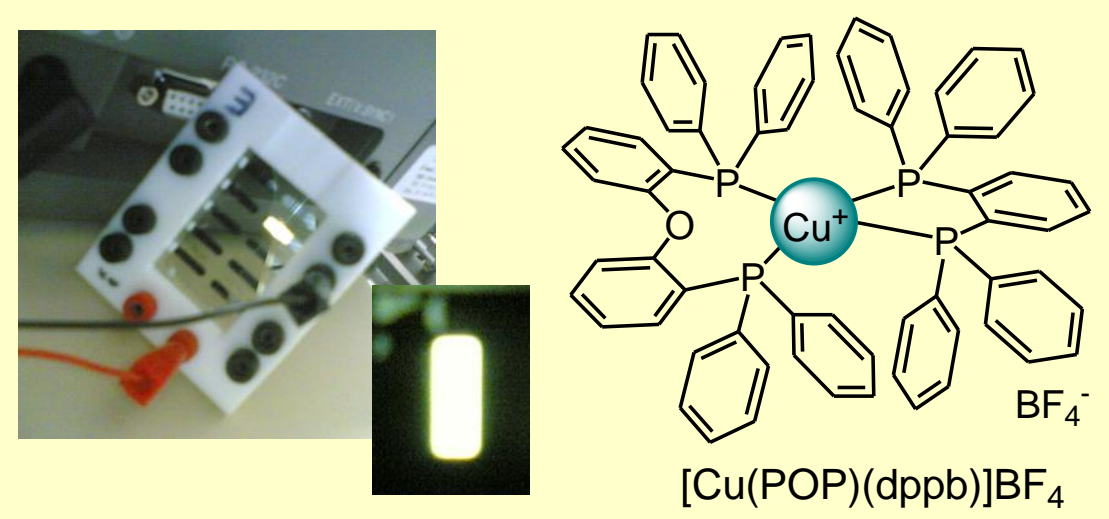

Homo- and heteroleptic copper(I) complexes obtained from various chelating bis-phosphine ligands and $\mathrm{Cu}\left(\mathrm{CH}_{3} \mathrm{CN}\right)_{4} \mathrm{BF}_{4}$ have been used for the preparation of light emitting devices. 